\title{
Erratum to: Downward longwave radiation estimates for clear and all-sky conditions in the Sertãozinho region of São Paulo, Brazil
}

\author{
Nadiane Smaha Kruk • Íria Fernandes Vendrame • \\ Humberto Ribeiro da Rocha • Sin Chan Chou • \\ Osvaldo Cabral
}

Published online: 25 September 2010

(C) Springer-Verlag 2010

\section{Erratum to: Theor Appl Climatol \\ DOI 10.1007/s00704-009-0128-7}

Owing to an unfortunate oversight, the name of the second author contained an error.

Fernades should read Fernandes.

The online version of the original article can be found at http://dx.doi. org/10.1007/s00704-009-0128-7.

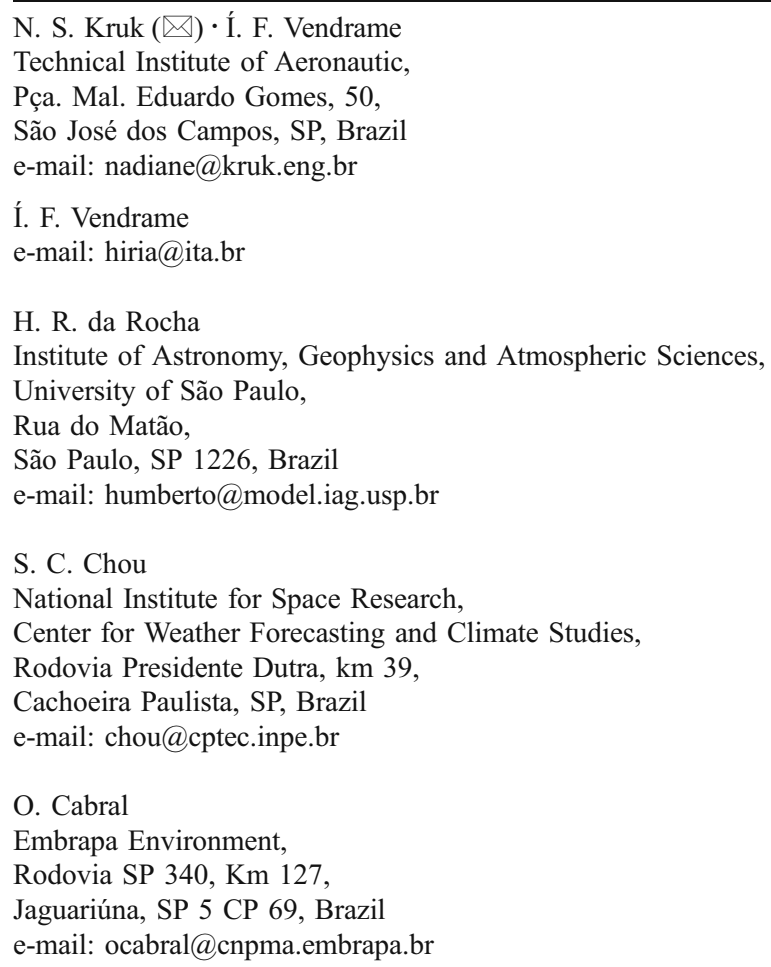

